\title{
The Milk Protein Alpha-Casein Suppresses Triple Negative Breast Cancer Stem Cell Activity Via STAT and HIF-1alpha Signalling Pathways in Breast Cancer Cells and Fibroblasts
}

\author{
Kirsten E. L. Garner ${ }^{1,2} \cdot$ Nathan J. Hull ${ }^{2} \cdot$ Andrew H. Sims ${ }^{3} \cdot$ Rebecca Lamb $^{4} \cdot$ Robert B. Clarke ${ }^{2}$
}

Received: 18 April 2019 / Accepted: 22 August 2019/Published online: 12 September 2019

(C) The Author(s) 2019

\begin{abstract}
Triple negative breast cancer (TNBC) is the most lethal breast cancer subtype. Extended periods of lactation protect against breast cancer development, but the mechanisms underlying this protection are unknown. We examined the effects of the milk protein alpha-casein over expression in the triple negative MDA-MB-231 breast cancer cell line. The effects of recombinant alpha-casein added exogenously to MDA-MB-231 breast cancer cells, and immortalised human fibroblasts were also investigated. We used transcriptional reporters to understand the signalling pathways downstream of alpha-casein in breast cancer cells and these fibroblasts that were activated by breast cancer cells. To extend our findings to the clinical setting, we analysed public gene expression datasets to further understand the relevance of these signalling pathways in triple negative breast cancer cells and patient samples. Finally, we used small molecular inhibitors to target relevant pathways and highlight these as potential candidates for the treatment of TN breast cancer. High levels of alpha-casein gene expression were predictive of good prognosis across 263 TNBC patient tumour samples. Alpha-casein over expression or exogenous addition reduces cancer stem cell (CSC) activity. HIF-1alpha was identified to be a key downstream target of alpha-casein, in both breast cancer cells and activated fibroblasts, and STAT transcription factors to be upstream of HIF-1alpha. Interestingly, HIF-1alpha is regulated by STAT3 in breast cancer cells, but STAT1 is the regulator of HIF-1alpha in activated fibroblasts. In analysis of 573 TNBC patient samples, alpha-casein expression, inversely correlated to HIF-1alpha, STAT3 and STAT1. STAT1 and STAT3 inhibitors target HIF-1alpha signalling in activated fibroblasts and MDA-MB-231 breast cancer cells respectively, and also abrogate CSC activities. Our findings provide an explanation for the protective effects of lactation in TNBC. Clinical data correlates high alpha-casein expression with increased recurrence-free survival in TNBC patients. Mechanistically, alpha-casein reduces breast cancer stem cell activity in vitro, and STAT3 and STAT1 were identified as regulators of pro-tumorigenic HIF-1alpha signalling in breast cancer cells and fibroblasts respectively.
\end{abstract}

Keywords Breast cancer stem cells $\cdot$ Cancer activated fibroblasts $\cdot$ HIF-1alpha. STAT

Electronic supplementary material The online version of this article (https://doi.org/10.1007/s10911-019-09435-1) contains supplementary material, which is available to authorized users.

Kirsten E. L. Garner

Kirsten.garner@manchester.ac.uk

1 Present address: Faculty of Biology, Medicine and Health, Michael Smith Building, University of Manchester, Dover Street,

Manchester M13 9PT, UK

2 Breast Biology Group, Breast Cancer Now Research Unit, Division of Cancer Sciences, Manchester Cancer Research Centre, University of Manchester, Manchester M20 4GJ, UK

3 Applied Bioinformatics of Cancer Institute of Genetics and Molecular Medicine, University of Edinburgh Cancer Research UK Centre, Edinburgh, UK

4 Division of Evolution and Genomic Sciences, School of Biological Sciences, University of Manchester, Manchester, UK

$\begin{array}{ll}\text { Abbreviations } \\ \text { TNBC } & \text { Triple negative breast cancer } \\ \text { CAF } & \text { Cancer associated fibroblast } \\ \text { BCSC } & \text { Breast cancer stem cell } \\ \text { TME } & \text { Tumour microenvironment } \\ \text { RFS } & \text { Recurrence free survival } \\ \text { ER } & \text { Estrogen receptor } \\ \text { PR } & \text { Progesterone receptor }\end{array}$

\section{Background}

Breast cancer is the most common malignancy, and the biggest cancer-related killer of women worldwide [1]. Risk factors such as early menarche, late menopause, and late first pregnancy (after 30) are all associated with an increase in 
breast cancer risk [2-4]. Inversely, early first pregnancy, multiple births and extended periods of lactation confer a reduced risk of developing breast cancer [5]. Notably, the protective effects of lactation are most profound in the aggressive triple negative subgroup $[2,3,6]$, but the physiological reasons for this phenomenon remain unclear.

Triple negative breast cancer (TNBC), as defined by the lack of estrogen (ER), progesterone receptors (PR) and low expression of HER2 receptor [7] is the most lethal breast cancer, and there are currently no convincing targeted therapies [8] By definition, TNBC is not treatable by common targeted anti-cancer drugs, as they lack the receptors capable of responding to them. A signature of this subgroup is an enrichment for CD24+/ CD44+ and ALDH1 [9, 10], which confer a breast cancer stem cell phenotype [11]. Breast cancer stem cells (BCSC) are a small population of cells that reside within the tumour mass that are capable of self-renewal, but also to repopulate all the cell types within the heterogeneous tumour mass $[12,13]$. $\mathrm{BCSC}$ possess increased tumour initiating properties and metastatic potential [14]. BCSC are proposed to be responsible for the chemotherapy resistance and lethal metastasis associated with TNBC, and the targeting of such cells is a promising strategy in its treatment.

Another factor important in tumour progression is the tumour microenvironment (TME). One of the most abundant cell types in the TME are fibroblasts, which become 'activated' by surrounding cancer cells to acquire a 'cancer associated fibroblast' (CAF) phenotype [15, 16]. CAFs are phenotypically different to their normal fibroblast counterparts, and are defined by expression of alpha-smooth muscle actin (alphaSMA) and fibroblast activation protein-alpha (FAP-alpha) $[17,18]$. CAFs promote cancer progression by providing secretory factors that promote migration and invasion $[19,20]$, and to promote the BCSC phenotype [21].

Extended periods of lactation are protective against TNBC. The milk protein alpha-casein was shown to reduce tumour burden and experimental lung metastasis when over expressed in mouse Met-1 tumour cells (22). In the present study, we assessed the effects of alphacasein on BCSC activity in vitro and found alpha-casein to significantly reduce BCSC in the triple negative MDAMB-231 cell line. Mechanistically, we showed this activity to be mediated by HIF-1alpha, a hypoxia inducible transcription factor closely associated with the induction and maintenance of a BCSC phenotype [23-25]. We further investigated the effects of alpha-casein on the TME and show alpha-casein to also regulate HIF-1alpha signalling in CAFs. We identified STAT3 and STAT1 to be crucial transcription factors in regulating HIF-1alpha in breast cancer stem cells and CAFs respectively, and used inhibitors to demonstrate their roles in HIF-1alpha regulation and CSC activity.

\section{Methods}

\section{Cell Lines and Culture}

The human MDA-MB-231 mammary tumour cells were obtained from ATCC (ATCC@ HTB-26 $6^{\mathrm{TM}}$ ). The human hTERT immortalised human fibroblasts (BJ1) were obtained from CLONTECH Laboratories (CCD00309196). Cell lines were passaged for $<25$ passages and regularly checked for mycoplasma. Cells were cultured in complete DMEM (SigmaAldrich) supplemented with $10 \%$ heat inactivated foetal bovine serum, 2 mM GlutaMAX (L-alanyl-L-glutamine), $100 \mathrm{U} /$ $\mathrm{ml}$ Penicillin and $100 \mu \mathrm{g} / \mathrm{ml}$ Streptomycin and incubated at $37{ }^{\circ} \mathrm{C}$ with $5 \% \mathrm{CO}_{2}$. All incubations performed at $37^{\circ} \mathrm{C}$ with $5 \% \mathrm{CO}_{2}$.

\section{Stable Cell Line Generation}

All stable cell lines were generated using lentiviral transduction. Alpha-casein (EX-S0252-Lv105) and empty vector control (EX-NEG-Lv105) expression plasmids were purchased from GeneCopoeia. Lentiviral particles were produced using the Lenti-Pac HIV expression Packaging kit and 293 Ta packaging cells both obtained from GeneCopoeia as per manufacturers' instructions, and viral supernatant was used to infect target cells. Pre-made Cignal ${ }^{\mathrm{TM}}$ Lenti reporter constructs purchased from Qiagen and used to infect target cells to generate stable reporter cell lines as per the manufacturer's instructions. These reporter constructs consist of a luciferase reporter gene fused to the applicable transcriptional response element (TRE) for each signalling pathway (details Table 1), and are used to quantitatively measure changes in signalling pathway activation in response to different stimuli. Two days following infection, successfully transduced cells were selected for using $2 \mu \mathrm{g} / \mathrm{ml}$ Puromycin or $1 \mathrm{mg}$ G418 Geneticin ${ }^{\circledR}$ for 14 days.

\section{Production of Conditioned Media}

$2 \times 10^{4}$ cells $/ \mathrm{cm}^{3}$ were cultured in $7.5 \mathrm{ml} / \mathrm{cm}^{3}$ of low serum (Nu-serum) media for 48 H. media was collected and centrifuged to remove debris and supernatant collected.

\section{Western Blotting}

Primary Antibodies Human alpha-casein antibody F20.14 (Abcam ab47972). STAT1 \#9172, Phospho-STAT1 (Tyr 701) \#9167, Phospho-STAT3 (Tyr 705) \#9131 purchased from Cell Signalling $(1: 1000)$. $\beta$-actin loading control (Sigma-Aldrich A2228) (1:10000).

Cell lysates were collected using RIPA lysis buffer (SigmaAldrich) with cOmplete ULTRA protease inhibitor (Roche) 
Table 1 Transcriptional response elements used in luciferase reporter constructs

\begin{tabular}{llll}
\hline Reporter construct & Pathway & Transcription factor & TRE \\
\hline Cignal lenti ISRE reporter (luc) CLS-008 L & Type I IFN & STAT1/STAT2 & TAGTTTCACTTTCCC \\
Cignal lenti GAS reporter (luc) CLS-009 L & Type II IFN & STAT1/STAT1 & AGTTTCATATTACTCTAAATC \\
Cignal lenti STAT3 (luc) CLS-6028 L & STAT3 & STAT3 & GTCGACATTTCCCGTAAATCGTCGA \\
Cignal lenti NF-kB (luc) CLS-013 L & NF-kB & NF-kB & GGGACTTTCC \\
Cigna lenti HIF-1 $\alpha$ (luc) CLS-007 L & Hypoxia & HIF-1 $\alpha$ & TACGTGCT \\
\hline
\end{tabular}

and PhosSTOP (Roche) phosphatase inhibitor. $20 \mu \mathrm{g}$ protein sample was loaded onto $12 \%$ polyacrylamide gel and transferred to nitrocellulose membranes. Membrane was blocked in $5 \%$ bovine serum albumin for $1 \mathrm{~h}$ at room temperature and then probed with primary antibody, diluted 1:1000 in blocking solution, and incubated at $4{ }^{\circ} \mathrm{C}$ overnight. Anti-mouse or antirabbit secondary antibodies (1:500) were added and incubated at room temperature for $1 \mathrm{~h}$. Protein was detected using SuperSignal ${ }^{\mathrm{TM}}$ West Pico or SuperSignal ${ }^{\mathrm{TM}}$ West Dura chemiluminescent Substrate (ThermoFisher) and developed on Kodak film.

\section{Mammosphere Assay}

Non-adherent mammosphere culture plates were made by covering clear 6 well plates with $2 \mathrm{ml}$ poly-HEMA and incubated at $60{ }^{\circ} \mathrm{C}$ for 3 days. Cells were syringed through a 25 gauge needle to provide cells in single cell suspension. A 1:1 volume of Trypan blue was used to count viable cells, and $5 \times 10^{3}$ single cells added to each well in DMEM/F-12 (Sigma-Aldrich) with B27 supplement, $20 \mathrm{ng} / \mathrm{ml} \mathrm{EGF}$ and $100 \mathrm{U} / \mathrm{ml}$ Penicillin and $100 \mu \mathrm{g} / \mathrm{ml}$ Streptomycin. Plates were then incubated for 5 days, and spheres $>50 \mu \mathrm{M}$ counted at $10 \mathrm{x}$ magnification. The mammosphere formation efficiency (MFE) was calculated by dividing the number of spheres $>50 \mu \mathrm{M}$ after 5 days by the number of cells seeded, and is expressed as a percentage.

\section{ALDEFLUOR $^{\text {Tm }}$ Assay}

$2 \times 10^{5}$ cells were incubated with or without drug treatment for 48 h. $2 \times 10^{5}$ were re-suspended in $1 \mathrm{ml}$ Dublecco's PBS. Dry Aldefluor reagent was reconstituted as per manufacturers' instructions. $5 \mu \mathrm{l}$ Aldefluor reagent was added and $500 \mu \mathrm{l}$ sample removed and added to a fresh eppendorf tube containing $10 \mu \mathrm{LEAB}$ to stop the reaction. This is the control sample. Cells were then incubated at $37^{\circ} \mathrm{C}, 5 \% \mathrm{CO}_{2}$ for $40 \mathrm{~min}$, and centrifuged at $4{ }^{\circ} \mathrm{C}$. Cell pellets were then re-suspended in $500 \mu \mathrm{l}$ Aldefluor assay buffer and analysed using the BD Laser Fortessa cell analyser (Biosciences).

\section{Luciferase Reporter Assays}

$5 \times 10^{3}$ reporter cells were seeded in triplicate in 96 well black plates and incubated overnight. Culture medium was removed and cells washed with PBS, and $100 \mu$ control media, conditioned media or drug treatment was then added. Plates were then incubated for 24,48 or $72 \mathrm{~h}$ as per experimental design. Reporter cells were fluorescently labelled to normalise luciferase activity. Following fluorescence reading, cells were lysed and luciferase activity measure using the Promega luciferase system and read on a IVIS ${ }^{\circledR}$ luminometer (PerkinElmer).

\section{PrestoBlue $^{\mathrm{TM}}$ Proliferation}

$1 \times 10^{4}$ cells per well were seeded in triplicate in 96 well black plates, and incubated for $8 \mathrm{~h}$ for cells to adhere. $20 \mu \mathrm{l}$ PrestoBlue ${ }^{\circ}$ reagent was added and incubated for $1 \mathrm{~h}$ and fluorescence (excitation $544 \mathrm{~nm}$, emission 621-10 nm) measured using a FLUOstart Omega microplate reader (BMG Labtech) for $\mathrm{T}=0$ timepoint. Further plates are incubated for 24, 48 and $72 \mathrm{~h}$, and fluorescence measured as before. Fluorescence readings were normalised by $\mathrm{T}=0 \mathrm{~h}$.

\section{Transwell Migration Assay}

$5 \times 10^{4}$ cells were added to the top of $8 \mu \mathrm{M}$ pore cell culture inserts (Transwells) (Falcon) placed in 24-well plates in serum-free media. Cells were allowed to migrate through the membrane for $6 \mathrm{~h}$ at $37^{\circ} \mathrm{C}$, towards $10 \%$ foetal bovine serum placed in the bottom wells to serve as chemoattractant. Noninvasive cells were removed from the top of the wells using cotton swabs, and migrated cells stained with crystal violet solution. After 20 min, wells were washed in $\mathrm{H}_{2} \mathrm{O}$ and membranes left to dry overnight. The number of migrated cells was calculated using a bright-field microscope, where the number of cells in six fields of view per membrane (20x objective) were counted. An average number was calculated over 3 independent experiments, in duplicate, carried out on independent days. 


\section{Statistical Methods}

All graphs were produced in Graphpad Prism 7, and this software was used for statistical analysis. Data are shown using the standard error of the mean $( \pm \mathrm{SEM})$, taken over 3 biological replicates with 2 or 3 technical replicates. Statistical significance was calculated using parametric testing, assuming equal variance, with un-paired Student's t test used to confirm statistical significance. Statistical significance was governed as a $p$ value $<=0.05$. Gene expression levels of alpha-casein signalling genes were retrieved from 17 Affymetrix datasets integrated to remove batch effects as previously described [26]. Similarly, Affymetrix gene expression data from three breast cancer cell line panel studies were integrated as described previously [26]. Cox proportional hazards survival analysis was performed for all possible points-of-separation (low-high cut-off points) for each gene (Pearce DA, Nirmal AJ, Freeman TC, Sims AH. Continuous biomarker assessment by exhaustive survival analysis. bioRxiv 2017. doi: https://doi.org/10.1101/208660). Gene expression levels of alpha-casein between normal and invasive ductal carcinoma were explored with dataset GSE10780 [27].

\section{Results}

\section{Alpha-Casein Expression Correlates with Improved Clinical Outcome in Triple Negative Breast Cancer, and Reduces Breast Cancer Stem Cell Activity In Vitro}

Firstly, we observed that that alpha-casein expression in invasive ductal carcinomas is significantly lower than in normal breast duct tissue (Fig. 1a). We then used a compendium of integrated published gene expression analysis datasets to investigate the relationship of alpha-casein expression to relapse-free survival (RFS) in over 250 triple negative breast cancer patient samples. All possible cut-points were considered, with $45 / 261$ significantly $(p<0.05)$ associating lower alpha-casein expression levels with worse outcomes in terms of relapse-free survival (Fig. 1b). To elucidate the mechanisms for the observed clinical data, we generated stable MDA-MB231 cell lines over expressing alpha-casein (using lentiviral transduction and selection). Stable empty vector (EV) cell lines were generated as a control. It has previously been shown that alpha-casein reduces tumour growth and metastasis in vivo [22]. However, we found no effect on proliferation and migration in MDA-MB-231 cells (supplementary Figure $1 \mathrm{~A} \& \mathrm{~B})$. In order to test another mechanism to explain the in vivo results, we examined stem cell activity by assaying mammosphere formation. Figures 1 B\&F.i show that alphacasein expression reduces the mammosphere formation efficiency (MFE) of breast cancer cells by nearly half compared to EV control cells. Addition of purified alpha-casein at a concentration of $500 \mu \mathrm{g} / \mathrm{ml}$ also produced a strong inhibition of MFE (Fig. 1d). We wanted to examine if these effects were replicated in other TNBC cell lines, and show that alphacasein inhibits MFE of MDA-MB-453 cells (Fig. 1e\&f.ii) indicating that alpha-casein is not just protective in the MDA-MB-231 TNBC cell line. These in vitro findings are supported by the patient data presented in Fig. 4. However, alpha-casein did not affect MFE in the SUM149 triple negative breast cancer cells (Supplementary Figure 1D), showing that alpha-casein is not protective in all TNBC cell lines. The reasons for resistance to alpha-casein in the SUM149 TNBC cell line would require further investigation.

Next, we tested the effect of alpha-casein overexpression on ALDH enzyme activity using the Aldefluor assay. This has previously reported to be a marker of breast cancer stem cells, and predicts for poor clinical outcome [28]. alpha-casein overexpression reduces the population of ALDH positive cells by nearly half (Fig. 1f). These results suggest the antitumourigenic effects of alpha-casein in vivo [22] may partly be explained by the ability of alpha-casein to inhibit cancer stem cell activity.

\section{Alpha-Casein Functions Mechanistically to Target pro-Tumorigenic HIF-1alpha Signalling in Breast Cancer Cells and Fibroblasts}

We next wanted to investigate the cellular signalling mechanisms responsible for the inhibitory effects of alpha-casein on BCSC activity. HIF-1alpha stabilisation and upregulation promotes and maintains the BCSC phenotype via multiple mechanisms (Mathieu et al, 2011; Schwab et al, 2012; Zhang et al, 2016). NF-kB is a second well -established signalling pathway that is upregulated in breast cancer, and known to regulate SC activity (Iliopoulos et al, 2009; Iliopoulos et al, 2011; Rinkenbaugh and Baldwin, 2016; Shostak and Chariot, 2011). Thus, we sought to investigate alpha-casein effects on these key CSC signalling pathways in breast cancer.

Stable HIF-1alpha and NF-kB-promoter-luciferase reporter constructs were transduced into MDA-MB-231 cells using lentiviral transduction. MDA-MB-231 breast cancer cells were cultured with purified alpha-casein (versus BSA as a control) for up to $72 \mathrm{~h}$, and changes in cell signalling monitored. We show that alpha-casein inhibits HIF-1alpha signalling in MDA-MB-231 cells in a dose- dependent manner, and by greater than half after $72 \mathrm{~h}$ (Fig. 2a), but had no effect on NF-KB signalling (Supplementary figure $1 \mathrm{C}$ ). We used a similar lentiviral approach as above to generate reporter fibroblast cell lines to study the potential effects of breast cancer cells, and HIF-1alpha signals in the microenvironment. Hyperactivation of HIF-1alpha signalling in fibroblasts is a signature of adoption of a tumour-promoting CAF phenotype [20, 29-31]. We found that breast cancer cells activate HIF-1alpha in fibroblasts 
Fig. 1 Alpha-casein expression correlates with improved clinical outcome in triple negative breast cancer, is lower expressed in cancer tissue and reduces breast cancer stem cell activity in vitro. a The

expression level of alpha-casein is significantly $(p=7 \mathrm{e}-6)$ higher in normal breast ducts than invasive ductal cancer (IDC). b Gene expression analysis of 262 triple negative breast cancer patient samples shows that alpha-casein expression correlates with RFS over 15 years follow-up ( $p=$ 0.03). c Alpha-casein expression reduces the mammosphere formation efficiency (MFE) of triple negative breast cancer cells (MDA-MB-231) by 0.62 fold compared to empty vector (EV) control cells. d $500 \mu \mathrm{g} / \mathrm{ml}$ of purified alpha-casein applied exogenously reduces the ability of MDA-MB-231 cells and e MDAMB-453 triple negative breast cancer cells to form spheres. All $n=9$. $\mathbf{f}$ Representative images of spheres after 5 days in nonadherent culture f.i alpha-casein expression versus empty vector control in MDA-MB-231 cells. f.ii $500 \mu \mathrm{g} / \mathrm{ml}$ alpha casein reduces the abilty of MDA-MB-453 cells to form spheres. $\mathrm{g}$ Alphacasein expression reduces the population of bright ALDH positive MDA-MB-231 cells by 0.6 fold over an average of 3 independent experiments, in duplicate, compared to EV control. $n=$ 6. All $* \mathrm{p}<\mathrm{p} .05, * * * * p<0.0001$ vs controls

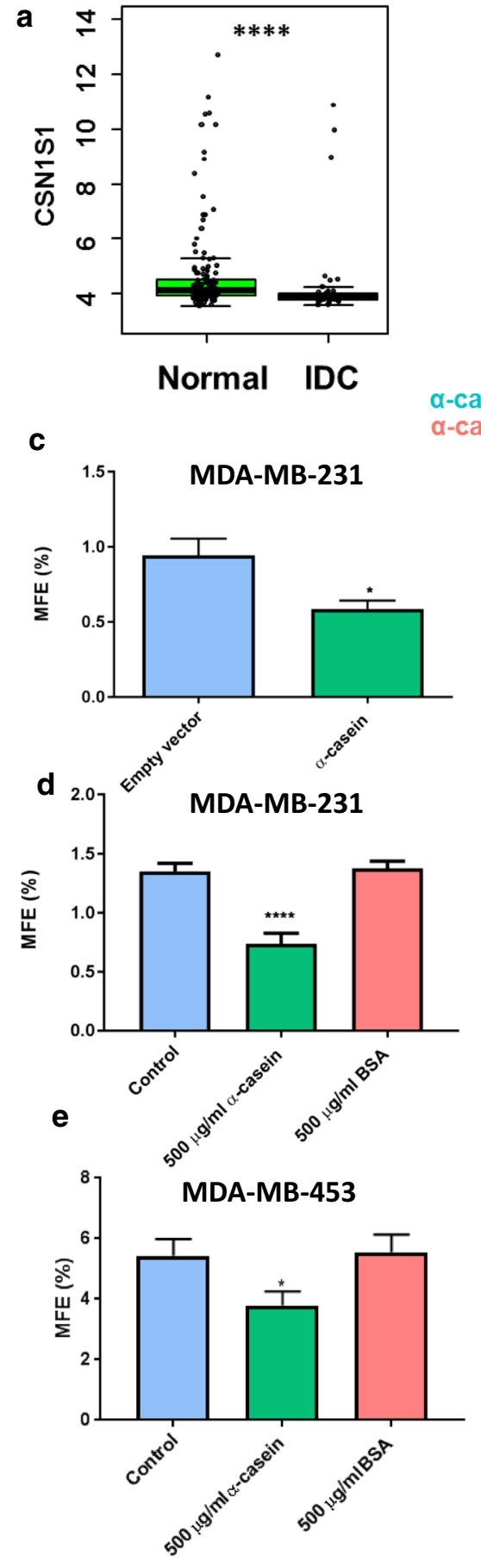

b

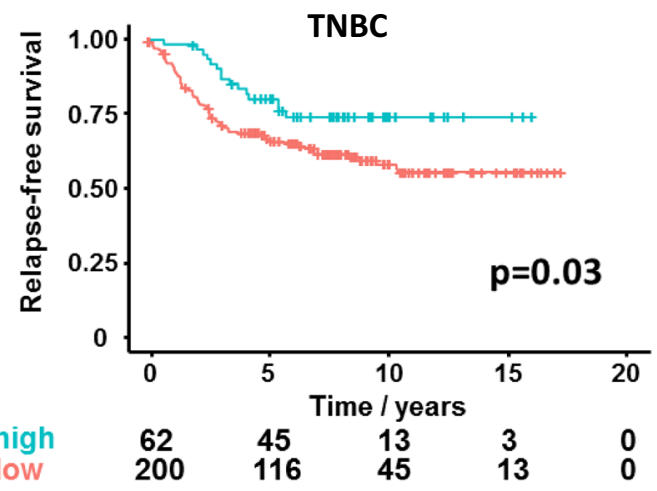

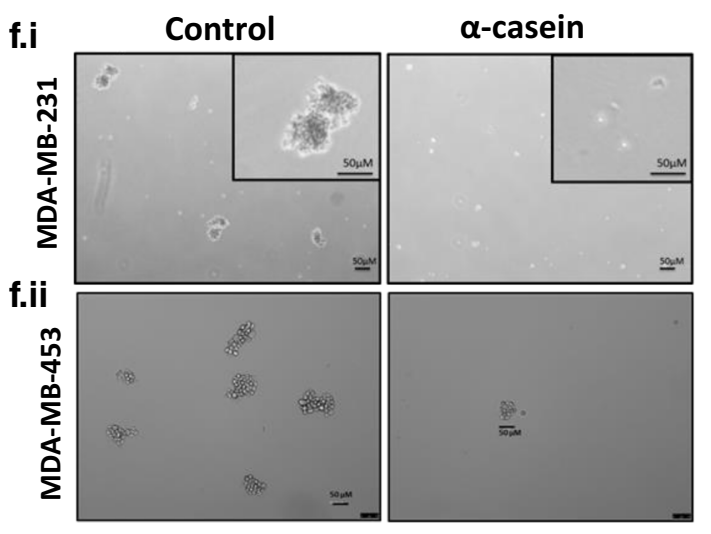

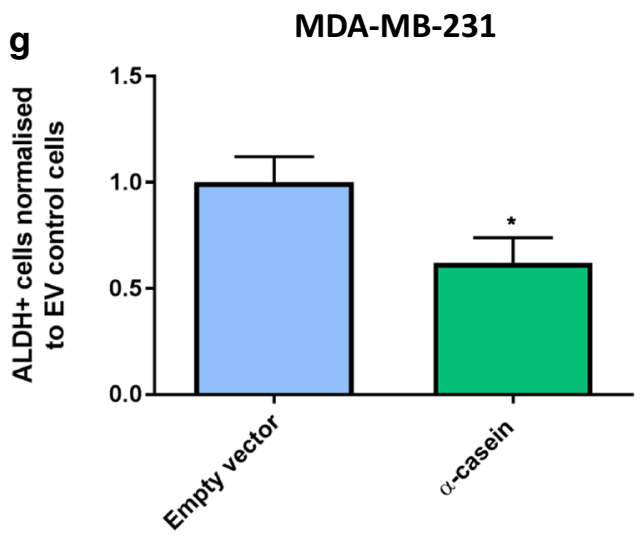

(Fig. 2b and c), an effect that is inhibited back to, or below basal levels following addition of alpha-casein. This suggests that alpha-casein is able to prevent the protumourigenic 'activation' of fibroblasts induced by breast cancer cells. Thus, HIF-1alpha, but not NFK $\beta$, is a key downstream target of alpha-casein but the mechanism for its activation is unknown. We note that fibroblasts are not exposed to milk proteins in intact homeostatic mammary tissue but envisage that in the context of mammary remodelling during lactation, weaning and involution, the fibroblasts will be exposed to milk that builds up in the ducts and leaks into the tumour microenvironment.

\section{Alpha-Casein Inhibits STAT3 and STAT1 in Breast Cancer Cells and Fibroblasts Respectively}

STAT3 is a strong candidate for HIF-1alpha regulation in breast cancer cells. Previous studies in breast cancer cells 
Fig. 2 Alpha-casein functions mechanistically to target protumorigenic HIF-1 alpha signalling in breast cancer cells and CAFs. a Alpha-casein reduces HIF-1alpha signalling in MDAMB-231 cells by greater than half after $72 \mathrm{~h}$ in a dose dependent manner. b Conditioned media collected from MDA-MB-231 cells activates HIF-1alpha signalling in fibroblasts. Alpha-casein reduces this activation back to, or below basal levels at 48 and $72 \mathrm{~h}$. c Representative images of bioluminescence data from $\mathbf{b}$ shown. All $n=9 * p<0.05, * * p<0.01$, $* * * p<0.001, * * * * \mathrm{p}<0.0001 \mathrm{vs}$ reporter alone controls
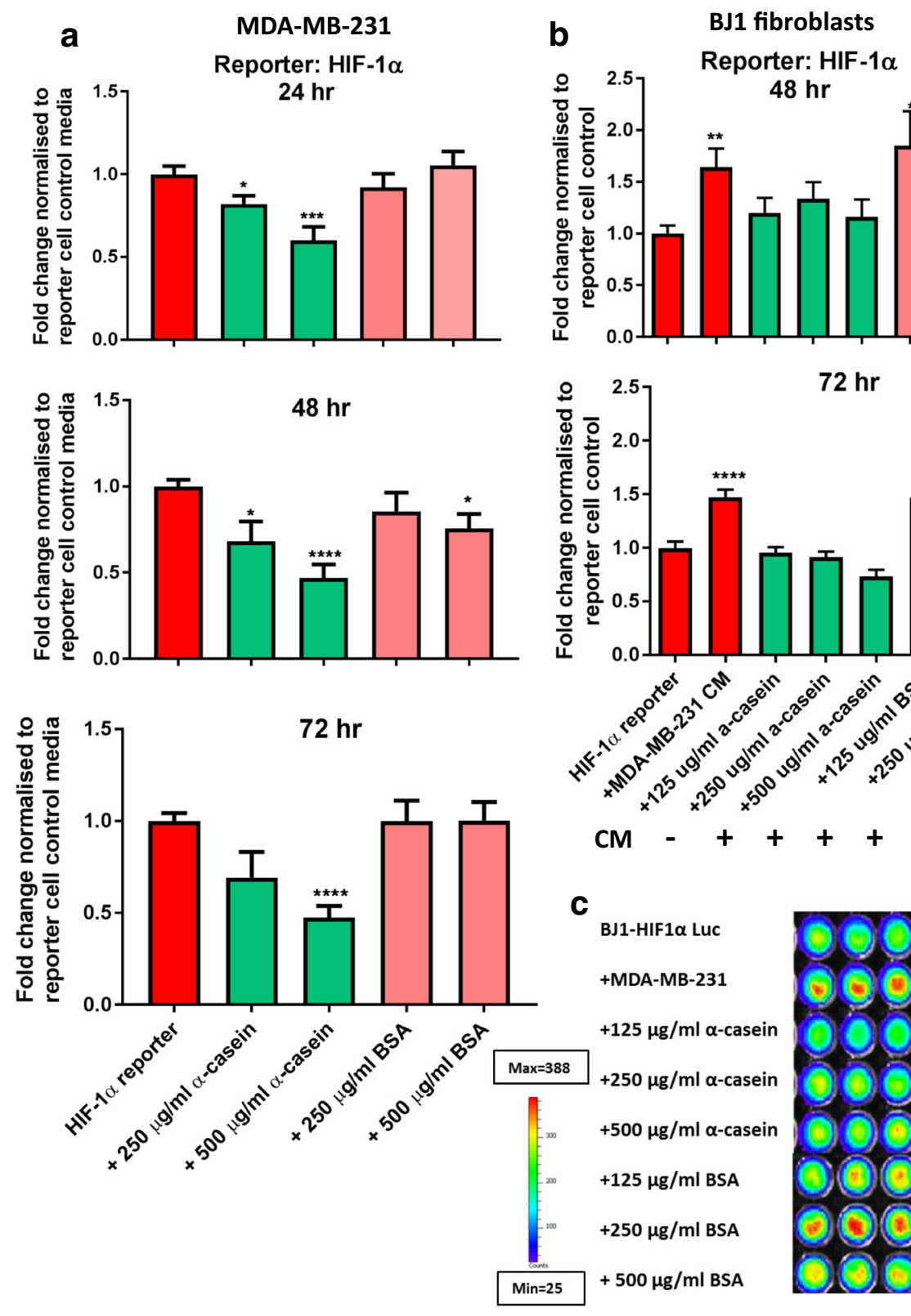

showed that STAT3 can regulate transcription of HIF-1alpha target genes directly [32], but that STAT3 and HIF-1alpha also work cooperatively to regulate HIF-1alpha target genes via the formation of an 'enhansome complex' with CREB binding protein and $\mathrm{p} 300$ [32].

To test this hypothesis, STAT3-luciferase reporter MDAMB-231 cells were cultured with conditioned media collected from control EV or alpha-casein overexpressing MDA-MB231 cells. Alpha-casein conditioned media reduces STAT3 reporter activity in breast cancer cells by greater than half, indicating less STAT3 activation (Fig. 3a). This was confirmed by western blot analysis which demonstrated 50\% less STAT3 phosphorylation (Fig. 3b). We found no effect on STAT3 activity in fibroblasts (data not shown). In contrast, we identified STAT1 as the signalling molecule upregulated in fibroblasts (Fig. 3 C\&D), but that its activation was inhibited by alpha-casein (Fig. 3 c\&d). Both the transcriptional and phosphorylation analyses establish that the targets of alpha-casein over expression are different in breast cancer cells compared to stromal fibroblasts.

\section{Alpha-Casein Expression Inversely Correlates with STAT1, STAT3 and HIF-1alpha in Basal Breast Cancer}

To confirm that alpha-casein signalling is relevant to all basal breast cancers, we considered expression of STAT1, HIF-1 alpha and STAT3 across three integrated breast cancer cell line panel datasets. Note that alpha-casein was not detectably 
Fig. 3 Alpha-casein inhibits STAT3 and STAT1 in breast cancer cells and fibroblasts respectively. a Conditioned media collected from alphacasein over expressing MDAMB-231 cells reduces STAT3 signalling in wild-type (WT) cells by greater than half $n=9$. $* \mathrm{p}<$ $0.05, * * * \mathrm{p}<0.001, * * * * \mathrm{p}<$ 0.0001 , vs reporter with conditioned media collected from EV control cells. b The activation of STAT3, as measured by the abundance of phospho-STAT3 (Tyr-705) was examined by western blot. $500 \mu \mathrm{g} / \mathrm{ml}$ alphacasein reduces STAT3 activation in MDA-MB-231 cells by an average of 0.6 fold over 2 independent experiments. $n=2$. c Conditioned media collected from MDA-MB-231 cells activates Type II IFN signalling in fibroblasts, as measured by activation of the STAT1 GAS luciferase reporter. Alpha-casein reduces this activation back to, or below, basal eves after $72 \mathrm{~h} . n=9$. $* * \mathrm{p}<0.01$, *** $\mathrm{p}<0.001$, **** $\mathrm{p}<0.0001$ vs reporter plus conditioned media d STAT1 activation was examined by western blot with an antibody directed against its active, phosphorylated form (Tyr- 701). $500 \mu \mathrm{g} / \mathrm{ml}$ alphacasein inhibits the activation of STAT1 in fibroblasts by breast cancer cell conditioned media. Average of 2 independent experiments shown in bottom quadrant. $n=2$. $* * * * \mathrm{p}<0.0001$ vs control media a

MDA-MB-231

Reporter: STAT3

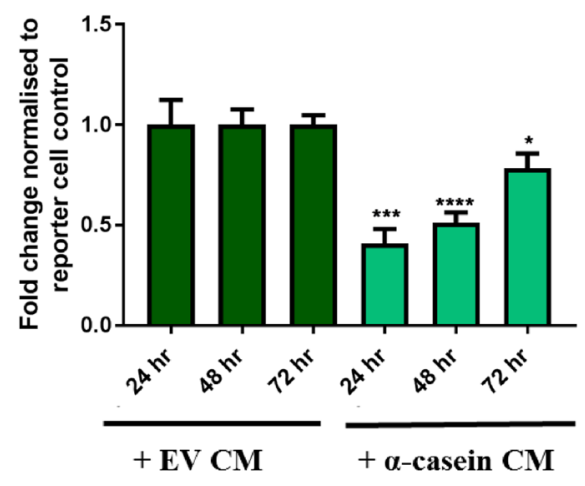

BJ1 fibroblasts

Reporter: STAT1 GAS
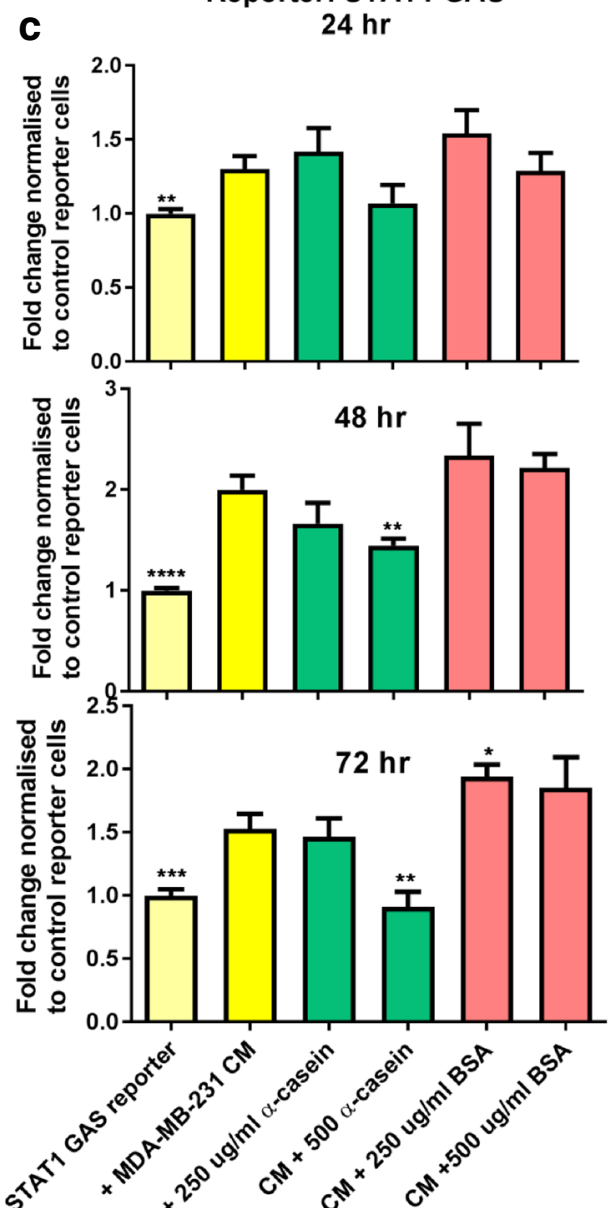

b

MDA-MB-231
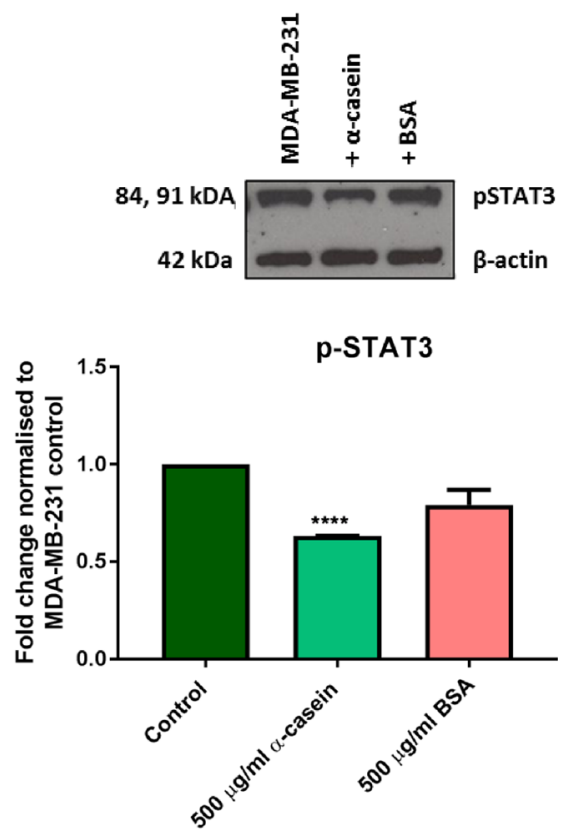

d BJ1 fibroblasts
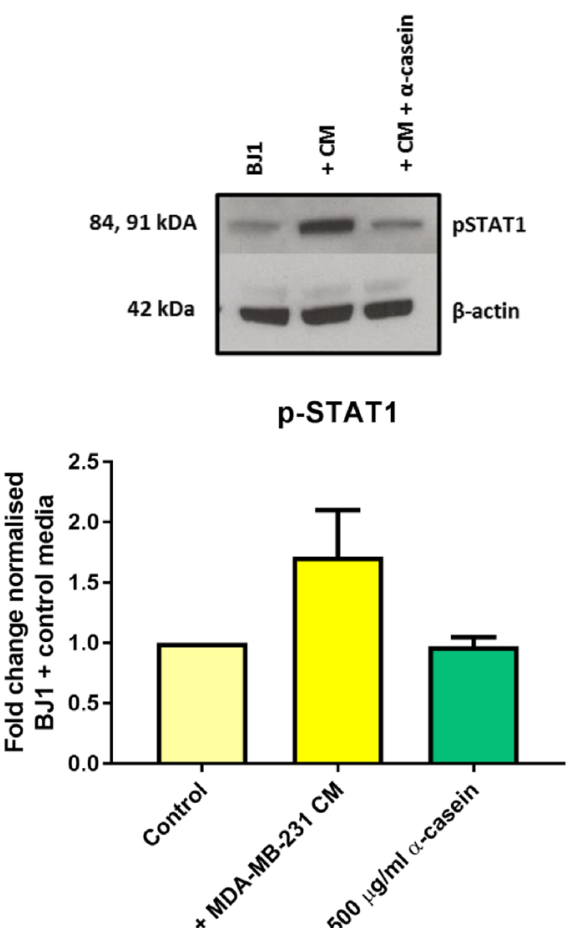

expressed across any of the cell lines. In accordance with our in vitro findings, the heatmap and boxplots in Fig. 4a demonstrate that HIF1-alpha, STAT3 and STAT1 have increased expression in the basal (TNBC) and claudin-low compared to the luminal breast cancer cell lines when comparing 83 different cell lines, 37 of which are triple-negative. This suggests this is a phenomenon across multiple triple-negative breast cancer subtypes. We next analysed the correlation between these genes and alpha-casein expression in TNBC patients. Analysis of 573 triple negative samples revealed that alphacasein expression is significantly, inversely correlated with HIF-1alpha, STAT3 and STAT1 (Fig. 4b) $(p<0.0001)$, suggesting the relevance of alpha-casein signalling in TNBC in the clinical setting. 
Fig. 4 alpha-casein expression inversely correlates with STAT3 and HIF-1alpha in basal breast cancer. a Heatmap and boxplots showing that HIF-1alpha, STAT1 and STAT3 are upregulated in triple negative and claudin-low breast cancer datasets using unsupervised clustering of 500 most variable genes in 3 integrated breast cancer cell line datasets. b Inverse correlation of HIF-1alpha, STAT1 and STAT3 versus alphacasein expression (CSNS1) in 573 TNBC patient samples (All $\mathrm{p}$ $<0.0001)$ a Gene expression levels across three integrated breast cell line datasets. Blue $=$ Luminal, Red=Basal A, Yellow=Claudin-low, orange $=$ Basal $B$, purple $=$ HER 2
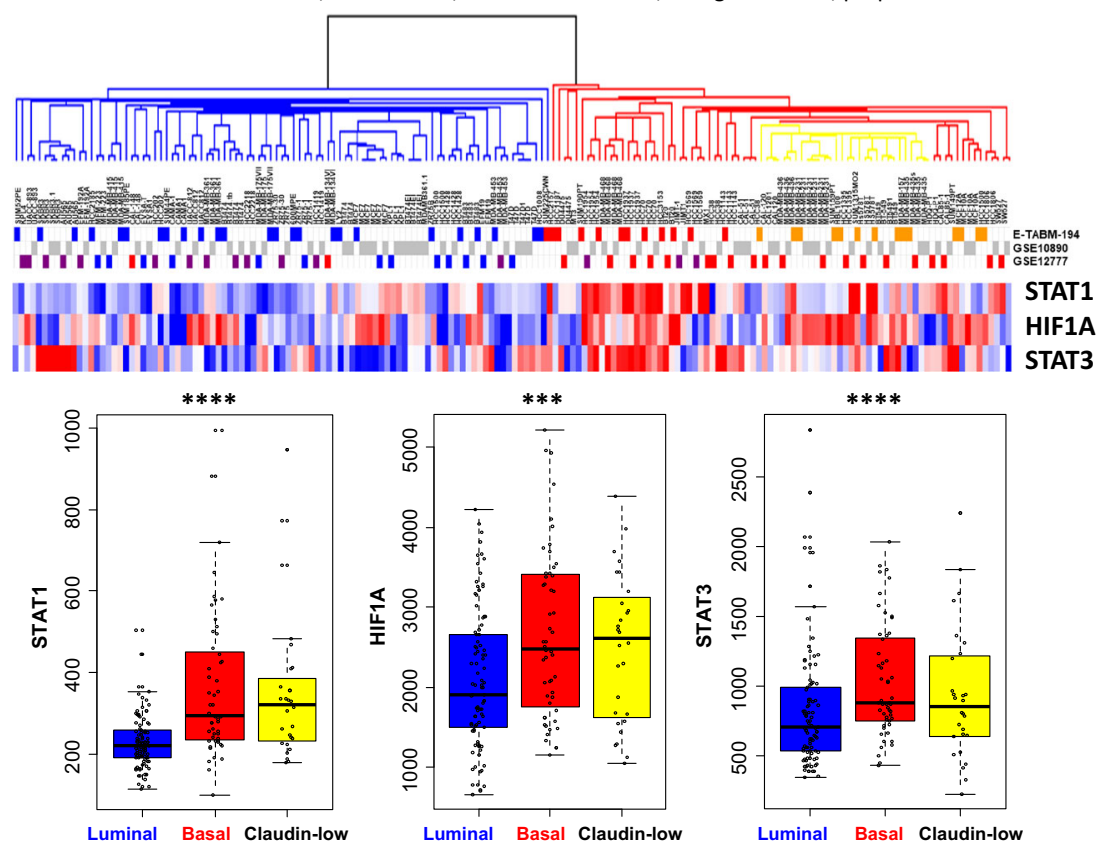

b Triple negative breast cancer patient gene expression data ( $N=573 \mathrm{TN}$ samples)
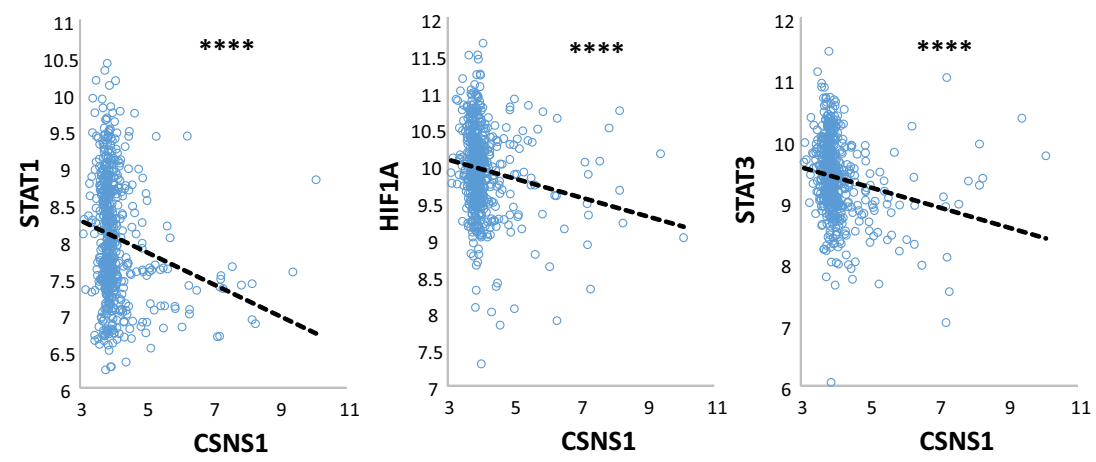

\section{STAT3 and STAT1 Function Upstream of HIF-1alpha in Breast Cancer Cells and Fibroblasts Respectively}

After identifying STAT3 and STAT1 to be potential candidates for HIF-1alpha regulation in breast cancer cells and fibroblasts, we next investigated their direct effect on HIF-1alpha signalling by using small molecule inhibitors of the STAT1 and STAT3 transcription factors. The inhibitors Niclosamide and Fludarabine were functionally active in inhibiting STAT3 and STAT1, respectively (Supplementary figure 2 A\&B respectively). STAT3 and STAT1 inhibition reduced HIF-1alpha transcriptional activity in both breast cancer cells (Fig. 5a) and fibroblasts following activation with conditioned media collected from MDA-MB-231 breast cancer cells (Fig. 5b). These results establish that STAT3 and STAT1 function upstream of HIF-1alpha in TNBC cells and fibroblast cells, respectively.

\section{Targeting STAT3 Reduces BCSC Activity}

Since STAT3 inhibition strongly abrogated HIF1-alpha signalling, we tested the effects of Niclosamide on BCSC activity using colony formation and ALDH activity. Niclosamide treatment significantly inhibited the MFE (\%) of MDA-MB231 cells by up to $70 \%$ at the highest concentration (Fig. $5 \mathrm{c} \&$ d). In addition, Niclosamide almost completely abolished ALDH activity in MDA-MB-231 cells (Fig. 5e). Therefore, we propose a model whereby alpha-casein acts directly on breast cancer stem cells, but also stromal cells of the tumour microenvironment by targeting HIF-1alpha (Fig. 6). Alphacasein inhibits STAT3 activity in breast cancer cells upstream of HIF-1alpha, which leads to a reduction in BCSC activity. Alpha casein also inhibits STAT1 in CAFs which reduces protumourigenc HIF-1alpha signalling in these cells. The inhibition of CSC activity of breast cancer cells by alpha-casein will further reduce tumorigenicity by abrogating the pro- 
Fig. 5 STAT3 and STAT1 function upstream of HIF1 alpha in breast cancer cells and fibroblasts respectively. a The STAT3 inhibitor Niclosamide inhibits HIF-1alpha signalling in MDA-MB-231 cells. b Similarly, the STAT1 inhibitor Fludarabine inhibits HIF-1alpha signalling in fibroblasts. c Niclosamide inhibits the MFE of MDA-MB-231 breast cancer cells by nearly half. All $n=9$. d Representative image of spheres after 5 days in nonadherent culture. e Niclosamide almost completely abolished the percentage of bright ALDH positive MDA-MB-231 cells. $n=6$. All ** $\mathrm{p}<0.01, * * * * \mathrm{p}<0.0001$ vs DMSO control
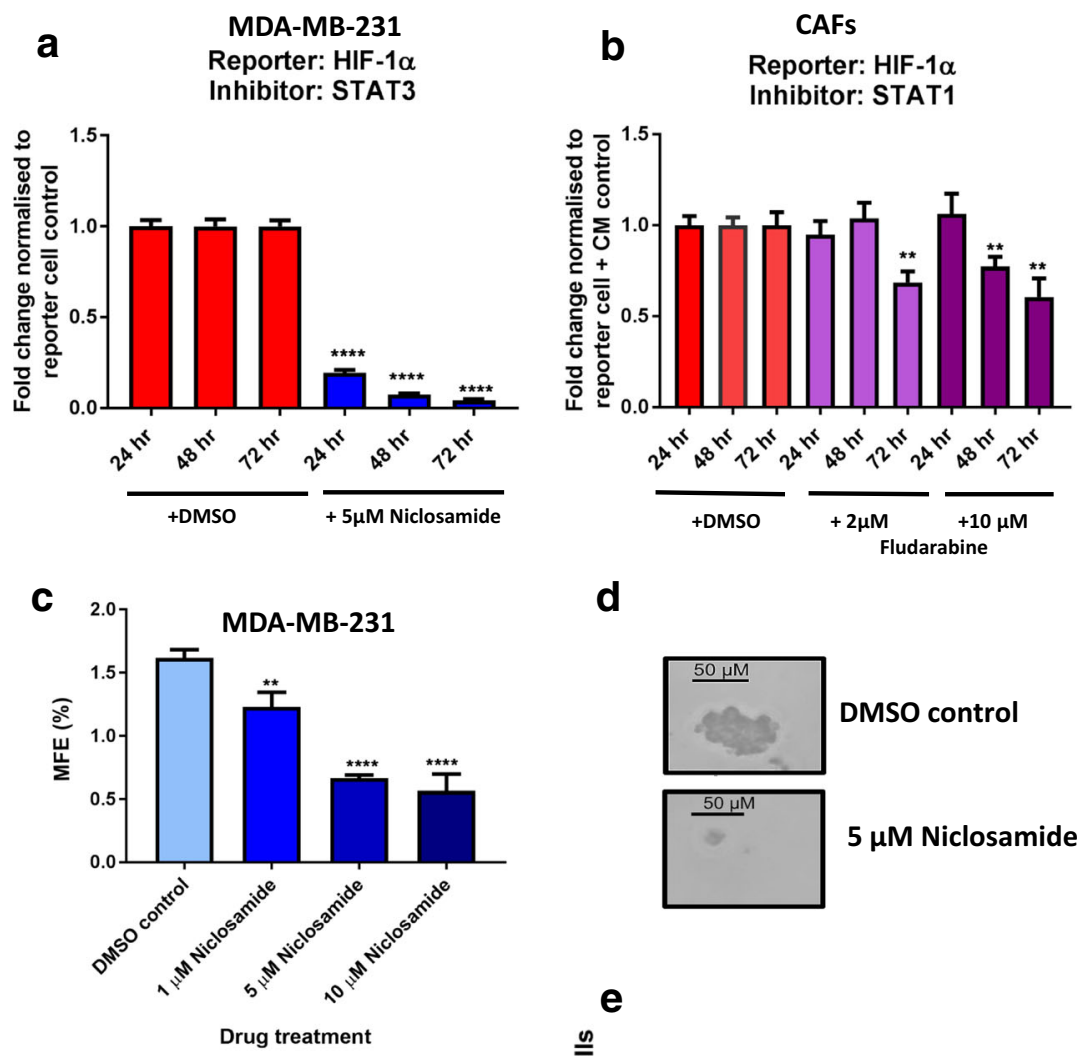

d
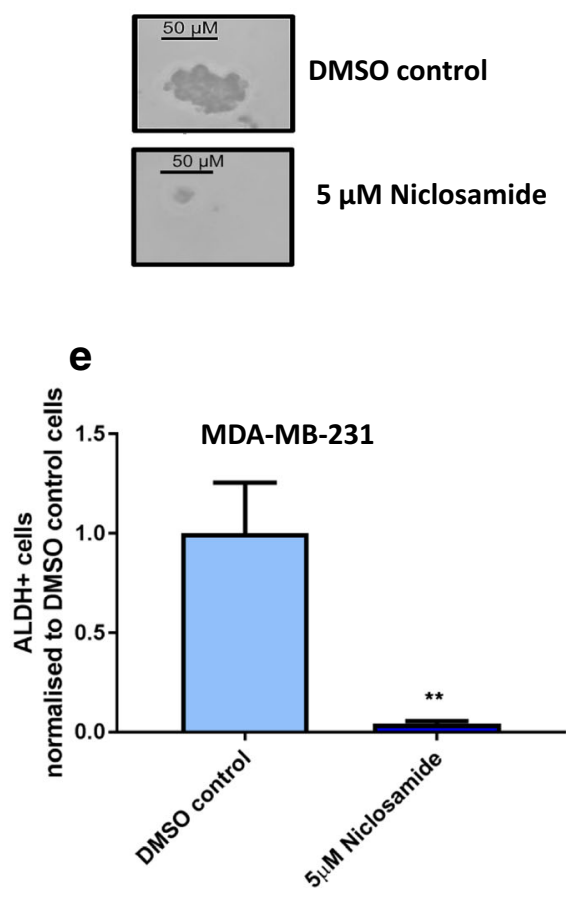

tumuiogenic bi-directional interaction between cancer stem cells and stromal neighbouring cells.

\section{Discussion}

TNBC is the most aggressive breast cancer subtype, and is associated with poor clinical outcome. A major factor governing this lethality is the propensity of TNBC to recur following chemotherapy $[33,34]$, metastasise $[35,36]$, and the lack of targeted therapy. One of the major factors responsible for this chemotherapy resistance, and thus high recurrence rates in TNBC is the enrichment of BCSC, particularly in this subtype $[9,10]$. Furthermore, chemotherapy, which is the current mainstay treatment for TNBC, has been shown to further enrich for cells with a BCSC phenotype [37, 38], with the activation of the hypoxia inducible factor HIF-1alpha being key in this response [39].

The inhibitory effects of the milk protein alpha-casein on mouse mammary tumour burden and experimental lung metastasis in vivo have previously been described [22]. There are a number of possible explanations why extended lactation could be protective, for example, limiting the exposure of the breast to the inflammatory environment of involution, or preventing potentially pre-cancerous cells from proliferating. If lactation is having a protective effect, it must be preventing transformation from normal to pre-cancerous cell, progression from pre-cancerous to tumour cell, or preventing growth and metastasis of the tumour. In this study, we have modelled the final lethal stage, where acquisition of a CSC phenotype promotes invasion and metastasis and provided functional explanation for these findings, where alpha-casein disrupts the CSC 
Fig. 6 Schematic representation of the proposed model of alpha-casein mode of action in protection of $T$ NBC. Alpha-casein has a dual role in inhibiting breast cancer progression via regulation of HIF-1alpha in TNBC. i) Alpha-casein has a direct effect on breast cancer cells by inhibiting STAT3 upstream of HIF-1alpha to reduce BCSC activity. ii) Alpha-casein also regulates HIF-1alpha in fibroblasts that have been activated by breast cancer cells via STAT1

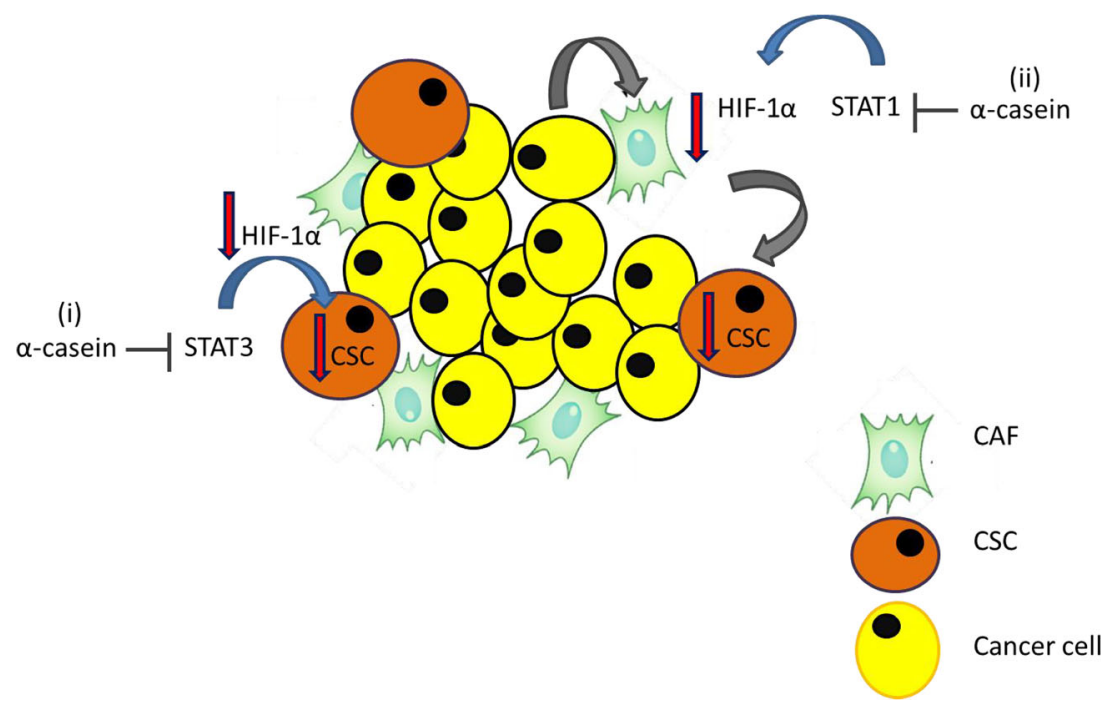

activity of MDA-MB-231 TNBC cells. In future studies it will therefore be important to test the effects of casein on earlier stages of progression.

A role of HIF-1alpha in the propagation and maintenance of this CSC phenotype has been reported [23, 24, 40], and this study further supports these ideas. We investigated the effects of alpha-casein on HIF-1alpha activation and signalling and found it to inhibit HIF1-alpha in TNBC cells, and that STAT3 is a regulator of HIF-1alpha signalling in this context. We used small molecule inhibitors of STAT3 to show its importance in the activation of HIF-1alpha in TNBC cells and downstream BCSC activity, where STAT3 and HIF-1alpha inhibition results in a $>70 \%$ reduction in CSC characteristics. STAT3 has previously been implicated in the promotion of CSC activity in hepatocellular carcinoma via activation of the Notch signalling pathway [21]. Herein we have found an alternative mechanism of STAT3 mediated CSC activation in breast cancer, where STAT3 phosphorylation at Y705 and concurrent activation increases BCSC via HIF-1alpha.

Interestingly, alpha-casein also inhibits HIF-1alpha signalling in fibroblasts that have been activated by breast cancer cells, but the mechanism of regulation is via a different STAT transcription factor in these cells, STAT1. As the adoption of this CAF phenotype via HIF-1alpha serves to promote cancer progression by providing metabolites and nutrients to energydemanding cancer cells $[41,42]$ and promoting a CSC phenotype [23, 24, 40], alpha-casein may also function via a feedforward inhibition of HIF-1alpha. Here, inhibition of HIF-1alpha signalling decreases the CSC activity, propagation and invasiveness of breast cancer cells, which in turn reduces CAFs in the surrounding stroma.

Thus, alpha-casein has a dual role on inhibiting breast cancer progression. We propose a mechanism (Fig. 6) whereby alpha-casein directly inhibits the CSC activity of transformed breast cancer cells via inhibition of STAT3 and HIF-1alpha.
Alpha-casein also inhibits HIF-1alpha in CAFs to abrogate the pro-tumorigenic reciprocal relationship between CAFs and BCSCs and ultimately cancer progression and metastasis.

\section{Conclusion}

We have provided mechanistic evidence as to how extended periods of lactation can potentially protect against TNBC. In the present study, we describe a new role of the milk protein alpha-casein as a negative regulator of CSC activity and transformation to a CAF phenotype in TNBC via HIF1alpha (Fig. 6). This work indicates that targeting STAT1 and STAT3 using small molecule drugs could be beneficial to patients in the clinic.

Acknowledgements We thank Priti Kalra, Ernestina DeFrancesco and Gloria Bonuccelli for technical assistance.

Author's Contributions KELG designed experiments, acquired, analysed and interpreted the data and drafted the manuscript, NJH performed some mammosphere experiments, RL designed experiments, AHS analysed gene expression data, RBC designed experiments, interpreted data and critically revised the manuscript.

Funding We acknowledge Breast Cancer Now (Grant MAN/Q2) and the NIHR Manchester Biomedical Research Centre (IS-BRC-1215-20007) for funding this project.

Data Availability Datasets used and/or analysed to support our findings are available from the corresponding author upon reasonable request. Datasets for patient samples are explicitly referenced where used, and in Statistical Methods.

\section{Compliance with Ethical Standards}

Ethics Approval and Consent to Participate Not applicable. 
Consent for Publication We have agreement from all authors (Kirsten Garner, Rebecca Lamb, Andy Sims and Robert Clarke) to submit this manuscript for publication.

Conflict of Interest The authors declare that they have no competing interests.

Open Access This article is distributed under the terms of the Creative Commons Attribution 4.0 International License (http:// creativecommons.org/licenses/by/4.0/), which permits unrestricted use, distribution, and reproduction in any medium, provided you give appropriate credit to the original author(s) and the source, provide a link to the Creative Commons license, and indicate if changes were made.

\section{References}

1. Torre LA, Bray F, Siegel RL, Ferlay J, Lortet-Tieulent JJA. Global cancer statistics, 2012. CA Cancer J Clin. 2015;65(2):87-108.

2. Li CI, Beaber EF, Tang MT, Porter PL, Daling JRMK. Reproductive factors and risk of estrogen receptor positive, triplenegative, and HER2-neu overexpressing breast cancer among women 20-44 years of age. Breast Cancer Res Treat. 2013;137(2):579-87.

3. Phipps AI, Malone KE, Porter PL, Daling JRLC. Reproductive and hormonal risk factors for postmenopausal luminal, HER-2-overexpressing, and triple-negative breast cancer. Cancer. 2008;113(7): $1521-2526$.

4. Tamimi RM, Colditz GA, Hazra A, Baer HJ, Hankinson SE, Rosner B, et al. Traditional breast cancer risk factors in relation to molecular subtypes of breast cancer. Breast Cancer Res Treat. 2012;131(1):159-67.

5. Möller T, Olsson H, Ranstam J. \& CG on HF in BC (2002). Breast cancer and breastfeeding: collaborative reanalysis of individual data from 47 epidemiological studies in 30 countries, including 50302 women with breast cancer and 96973 women without the disease. Lancet. 2002;360(9328):187-95.

6. Palmer JR, Viscidi E, Troester MA, Hong CC, Schedin P, Bethea $\mathrm{TN}$, et al. Parity, lactation, and breast cancer subtypes in African American women: results from the AMBER Consortium. J Natl Cancer Inst. 2014;106(10):dju237.

7. Foulkes WD, Smith IER-FJ. Triple-negative breast cancer. N Engl J Med. 2010;363(20):1938-48.

8. Cleator S, Heller WCR. Triple-negative breast cancer: therapeutic options. Lancet Oncol. 2007;8(3):235-44.

9. Honeth G, Bendahl PO, Ringnér M, Saal LH, Gruvberger-Saal SK, Lövgren $\mathrm{K}$, et al. The CD44+/CD24- phenotype is enriched in basal-like breast tumors. Breast Cancer Res. 2008;10(3):R53.

10. Ricardo S, Vieira AF, Gerhard R, Leitão D, Pinto R, CameselleTeijeiro JF, et al. Breast cancer stem cell markers CD44, CD24 and ALDH1: expression distribution within intrinsic molecular subtype. J Clin Pathol. 2011;64(11):937-46.

11. Al-Hajj M, Wicha MS, Benito-Hernandez A, Morrison SJ, Clarke MF. Prospective identification of tumorigenic breast cancer cells. Proc Natl Acad Sci U S A. 2003;100(7):3983-8.

12. Clarke MF, Dick JE, Dirks PB, Eaves CJ, Jamieson CH, Jones DL, et al. Cancer stem cells-perspectives on current status and future directions: AACR workshop on cancer stem cells. Cancer Res. 2006;66(19):9339-44.

13. Lehmann BD, Bauer JA, Chen X, Sanders ME, Chakravarthy AB, Shyr YPJ. Identification of human triple-negative breast cancer subtypes and preclinical models for selection of targeted therapies. J Clin Invest. 2011;121(7):2750-67.
14. Charafe-Jauffret E, Ginestier C, Iovino F, Wicinski J, Cervera N, Finetti $\mathrm{P}$, et al. Breast cancer cell lines contain functional cancer stem cells with metastatic capacity and a distinct molecular signature. Cancer Res. 2009;69(4):1302-13.

15. Cirri PCP. Cancer-associated-fibroblasts and tumour cells: a diabolic liaison driving cancer progression. Cancer Metastasis Rev. 2012;31(1-2):195-208.

16. Marsh T, Pietras KMS. Fibroblasts as architects of cancer pathogenesis. Biochim Biophys Acta. 2013;1832(7):1070-8.

17. Ao Z, Shah SH, Machlin LM, Parajuli R, Miller PC, Rawal S, et al. Cote R5, Lippman ME, Datar RH E-AD. Identification of Cancerassociated fibroblasts in circulating blood from patients with metastatic breast Cancer. Cancer Res. 2015;75(22):4682-7.

18. Kalluri R1 ZM. Fibroblasts in cancer. Nat Rev Cancer. 2006;6(5): 392-401.

19. De Francesco EM, Lappano R, Santolla MF, Marsico S, Caruso A, Maggiolini M. HIF- $1 \alpha /$ GPER signaling mediates the expression of VEGF induced by hypoxia in breast cancer associated fibroblasts (CAFs). Breast Cancer Res. 2013;15(4):R64.

20. Kalluri R. The biology and function of fibroblasts in cancer. Nat Rev Cancer. 2016;16:582-98.

21. Xiong S, Wang R, Chen Q, Luo J, Wang J, Zhao Z, et al. Cancerassociated fibroblasts promote stem cell-like properties of hepatocellular carcinoma cells through IL-6/STAT3/notch signaling. Am J Cancer Res. 2018;8(2):302-16.

22. Bonuccelli G, Castello-Cros R, Capozza F, Martinez-Outschoorn UE, Lin Z, Tsirigos A, et al. The milk protein $\alpha$-casein functions as a tumor suppressor via activation of STAT1 signaling, effectively preventing breast cancer tumor growth and metastasis. Cell Cycle. 2012;11(21):3972-82.

23. Mathieu J, Zhang Z, Zhou W, Wang AJ, Heddleston JM, Pinna CM, et al. BM. HIF induces human embryonic stem cell markers in cancer cells. Cancer Res. 2011;71:4640-52.

24. Schwab LP, Peacock DL, Majumdar D, Ingels JF, Jensen LC, Smith $\mathrm{KD}$, et al. Hypoxia-inducible factor $1 \alpha$ promotes primary tumor growth and tumor-initiating cell activity in breast cancer. Breast Cancer Res. 2012;14(1):R6.

25. Liu, Zhao-ji, Gregg L. Semenza and HZJ of ZUSB 16. (2015): 32 43. PW 16 D 2016. Hypoxia-inducible factor 1 and breast cancer metastasis. J Zhejiang Univ Sci B 2015;16(1):32-43.

26. Moleirinho S, Chang N, Sims AH, Tilston-Lünel AM, Angus L, Steele A, et al. KIBRA exhibits MST-independent functional regulation of the hippo signaling pathway in mammals. Oncogene. 2013;32(14):1821-30.

27. Chen DT, Nasir A, Culhane A, Venkataramu C, Fulp W, Rubio R, et al. Proliferative genes dominate malignancy-risk gene signature in histologically-normal breast tissue. Breast Cancer Res Treat. 2010;119(2):335-46.

28. Ginestier C, Hur MH, Charafe-Jauffret E, Monville F, Dutcher J, Brown $\mathrm{M}$, et al. ALDH1 is a marker of normal and malignant human mammary stem cells and a predictor of poor clinical outcome. Cell Stem Cell. 2007;1(5):555-67.

29. Esquivel-Velázquez M1, Ostoa-Saloma P, Palacios-Arreola MI, Nava-Castro KE, Castro JI M-MJ. The role of cytokines in breast cancer development and progression. J Interf Cytokine Res. 2015;35(1):1-16.

30. Hung SP, Ho JH, Shih YR, Lo TLO. Hypoxia promotes proliferation and osteogenic differentiation potentials of human mesenchymal stem cells. J Orthop Res. 2012;30(2):260-6.

31. Orimo AWR. Stromal fibroblasts in cancer: a novel tumorpromoting cell type. Cell Cycle. 2006;5(15):1597-601.

32. Pawlus M, Wang L, Hu C-J. STAT3 and HIF1 $\alpha$ cooperatively activate HIF1 target genes in MDA-MB-231 and RCC4 cells. Oncogene. 2014;33(13):1670-9. 
33. Dent R, Trudeau M, Pritchard KI, Hanna WM, Kahn HK, Sawka $\mathrm{CA}$, et al. Triple-negative breast cancer: clinical features and patterns of recurrence. Clin Cancer Res. 2007;13(15 pt 1):4429-34.

34. Lin NU, Vanderplas A, Hughes ME, Theriault RL, Edge SB, Wong $\mathrm{YN}$, et al. Clinicopathologic features, patterns of recurrence, and survival among women with triple-negative breast cancer in the national comprehensive Cancer network. Cancer. 2012;118(22): 5463-72.

35. Haffty BG, Yang Q, Reiss M, Kearney T, Higgins SA, Weidhaas J, et al. Locoregional relapse and distant metastasis in conservatively managed triple negative early-stage breast cancer. J Clin Oncol. 2006;24(36):5652-7.

36. Liedtke C, Mazouni C, Hess KR, André F, Tordai A, Mejia JA, et al. Response to neoadjuvant therapy and long-term survival in patients with triple-negative breast cancer. J Clin Oncol. 2008;26(8):1275-81.

37. Creighton CJ, Li X, Landis M, Dixon JM, Neumeister VM, Sjolund A, Rimm DL, Wong H, Rodriguez A, Herschkowitz JI, Fan C, Zhang X, He X, Pavlick A, Gutierrez MC, Renshaw L, Larionov AA, Faratian D, Hilsenbeck SG, Perou CM, Lewis MT, Rosen JM, Chang JC.Creig CJ. Residual breast cancers after conventional therapy display mesenchymal as well as tumor-initiating features. Proc Natl Acad Sci U S A 2009;106(33):13820-13825.

38. Li X, Lewis MT, Huang J, Gutierrez C, Osborne CK, Wu MF, et al. Li X1, Lewis MT, Huang J, Gutierrez C, Osborne CK, Wu MF,
Hilsenbeck SG, Pavlick a, Zhang X, Chamness GC, Wong H, Rosen J CJ. Intrinsic resistance of tumorigenic breast cancer cells to chemotherapy. J Natl Cancer Inst. 2008;100(9):672-9.

39. Conley SJ, Gheordunescu E, Kakarala P, Newman B, Korkaya H, Heath AN, et al. Antiangiogenic agents increase breast cancer stem cells via the generation of tumor hypoxia. Proc Natl Acad Sci U S A. 2012;109(8):2784-9.

40. Zhang C, Samanta D, Lu H, Bullen JW, Zhang H, Chen I, et al. Hypoxia induces the breast cancer stem cell phenotype by HIFdependent and ALKBH5-mediated m6A-demethylation of NANOG mRNA. Proc Natl Acad Sci U S A. 2016;113(14): E2047-56.

41. Pavlides S, Whitaker-Menezes D, Castello-Cros R, Flomenberg N, Witkiewicz AK, Frank PG, et al. The reverse Warburg effect: aerobic glycolysis in cancer associated fibroblasts and the tumor stroma. Cell Cycle. 2009;8(23):3984-4001.

42. Sotgia F, Martinez-Outschoorn UE, Pavlides S, Howell A, Pestell RGLM. Understanding the Warburg effect and the prognostic value of stromal caveolin- 1 as a marker of a lethal tumor microenvironment. Breast Cancer Res. 2011;13(4):213.

Publisher's Note Springer Nature remains neutral with regard to jurisdictional claims in published maps and institutional affiliations. 